\title{
Relationship between Spasticity and Motor Abilities in Children with Hemiplegia
}

\author{
ESRAA ABD EL-AZIZ, M.Sc.; AMIRA EL- TOHAMY, Ph.D. and ASMAA OSAMA, Ph.D. \\ The Department of Pediatric Physical Therapy, Faculty of Physical Therapy, Cairo University
}

\begin{abstract}
Background: Children with spastic hemiplegic cerebral palsy have limited activities of daily living, such as dressing, feeding, and functional mobility, due to problems of the upper limb and hand function. Their gait pattern is characterized by lower speed and lower single stance time in the most compromised limb, as well as reduced step length and limb asymmetry.

Aim of Study: To determine if there is a correlation between fine and gross motor abilities of hemiplegic children and their spasticity grade.

Methods: Eleven hemiplegic cerebral palsy children with mild and moderate spasticity were recruited from physical therapy outpatient clinic Cairo University and Abo-Elreesh Hospital; each child was assessed using Gross Motor Function Measure, Modified Ashwarth Scale and Manual Ability Classification System.

Results: There was no significant correlation between the spasticity grade and motor scales.

Conclusion: This article shows that the spasticity grade is not the main factor that affects gross and fine motor abilities of hemiplegic children.
\end{abstract}

Key Words: Spasticity - Motor abilities - Hemiplegia.

\section{Introduction}

CEREBRAL palsy (CP) is defined as a group of non-progressive disorders of movement and posture due to a defect or lesion in the developing brain [1]. Among children with cerebral palsy, $29 \%$ have hemiplegia, that is, one side of the body is affected much more than the other, and the upper limb is typically more involved than the lower limb [2]

Children with spastic hemiplegic $\mathrm{CP}$ experience problems of motor control, with inefficient movement patterns. Thus, they have a mass movement pattern and difficulty performing specific tasks. In addition, children with spastic hemiplegic $\mathrm{CP}$

Correspondence to: Dr. Esraa Abd El-Aziz,

The Department of Pediatric Physical Therapy, Faculty of Physical Therapy, Cairo University is limited with activities of daily living, such as dressing, feeding, and function mobility, due to problems of the upper limb and hand function [3]

The gait performance of children with spastic hemiplegia-type $\mathrm{CP}$, compared to that of normal children, is characterized by lower speed and lower single stance time in the most compromised limb, as well as reduced step length and limb asymmetry [4].

Such changes are most likely due to muscle weakness and impaired dexterity in the affected side of the body, which may hinder weight transfer to and weight bearing capacity of the affected limb during gait [5]

Children with hemiplegic CP suffer from spasticity, sensory deficit, and muscle weakness, affecting functions of the upper limb more than that of the lower limb. Decreased upper limb function in children with spastic hemiplegic $\mathrm{CP}$ reduces the efficiency of manipulative function [6] .

Spasticity was first described as 'a motor disorder characterized by a velocity dependent increase in tonic stretch reflexes (muscle tone) with exaggerated tendon jerks, resulting from hyper-excitability of the stretch reflex, as one component of the upper motor neuron syndrome [7].

Spasticity is the major problem encountered most frequently by pediatric physiotherapists. Spasticity makes the voluntary and selective motor control more difficult, increases energy consumption, and causes the formation of secondary musculoskeletal system problems observed in CP [8]

There are various clinical scales, biomechanical assessment tools, and neurophysiologic assessment methods to assess spasticity; however, there is no 
consensus about the best assessment. The most frequently used clinical scales are Ashworth / Modified Ashworth (MAS) and Tardieu/Modified Tardieu (MTS) scales. MTS grades muscle spasticity in three different velocities and goniometric measurements also included for all velocities [9] According to a study by Numanog lu et al., [10] the administration of MAS is easier and takes less time than MTS, but MTS gives valuable information about muscle length and dynamic contracture and has better intra-observer reliability.

The purpose of the current study was therefore to determine is there a correlation between gross and fine motor ability levels of hemiplegic children and their spasticity grade. Our hypothesis is that there is no correlation between gross and fine motor abilities levels and spasticity grade.

\section{Material and Methods}

Eleven cerebral palsy children were included in this cross section study to assess the correlation between motor ability level, degree of spasticity and the ability to handle objects in hemiplegic cp children who attended physical therapy outpatient clinic, Abo El-Reesh Hospital and national institute for neuro-motor system from September 2017 to Mars 2018. The inclusion criteria was to be mild and moderate spastic hemiplegic cerebral palsy children, their age ranged from five to twelve years old and their exclusion criteria was previous Botox injection for at least 6 months and surgical operations for at least one year.

The study was approved by the ethical committee of the Faculty of Physical Therapy, Cairo University, Egypt. As well as a written consent form from children's parents was obtained before starting the study.

Adapted form based on the Australian registration form for persons with $\mathrm{CP}$ was used for data collection.

\section{1- Gross Motor Function Classification System expanded and revised:}

The GMFCS-ER is a scale used to assess children with CP, It is arranged into five formative measurements which characterize the motor involvement of children with $\mathrm{CP}$ on the basis of their functional and walking abilities and their need for assistive technology and wheeled mobility [11]

The focus of the GMFCS-ER is on determining which level best represents the child's present abilities and limitations in gross motor function. Emphasis is on usual performance at home, school, and community settings (i.e., what they do), rather than what they are known to be able to do at their best (capability). It is therefore important to classify current performance in gross motor function and not to include judgments about the quality of movement or prognosis for improvement [12]

\section{2- Gross motor function measure-88:}

The motor function of children with CP is usually assessed using the GMFM-88. It is an evaluative, standardized, criterion-referenced observational instrument that was created to measure changes in gross motor function over time in individuals with $\mathrm{CP}$. This measure has been considered for its reliability (intra-rater, test-retest, and interrater) and validity [13]

The GMFM- 88 measures the child's skill in 88 items across five dimensions: (a) Lying and rolling, (b) Sitting, (c) Crawling and kneeling, (d) Standing, and (e) Walking, running and jumping, but does not measure the quality of the movement. All items in GMFM-88 usually could be accomplished by 5-years of age with normal motor abilities [14].

\section{3- Modified Ashworth scale}

The most commonly used test for spasticity in clinical practice is the modified Ashworth scale. The test is based on the assessment of resistance to passive stretch of muscle group at one nonspecified velocity [15]

\section{4- Manual ability classification system:}

The MACS is used to assess the manual ability of children between 4 and 18 years of age. It describes how children with CP use their hands to handle objects in daily activities. It is arranged into five levels. The levels are based on the children's self-initiated ability to handle objects and their need for assistance or adaptation to perform manual activities in everyday life. Level I include children with minor limitations, while children with severe functional limitations will usually be found at levels IV and V [16]

The MACS assesses the children's overall ability to handle everyday objects, not the function of each hand separately. It does not take into account differences in function between the two hands; rather, it addresses how the children handle ageappropriate objects. Moreover, it does not intend to explain the underlying reasons for impaired manual abilities [16] 
Procedures: Each child was assessed using:

\section{1-Modified Ashworth scale:}

This scale measures passive resistance in the joint, as the examiner perceives it. The resistance is scored from 0 to $5[\mathbf{1 7 , 1 8}]$

\section{2- Gross motor function measure-88:}

It was used to assess the child's motor performance. The evaluation room was large and quiet to encourage the child to perform the task with maximum effort.

It consists of 88 items related to gross motor abilities clustered into five dimensions: Lying and rolling (17 items); sitting (20 items); crawling and kneeling (14 items); standing (13 items); and walking, running, and jumping (24 items).

All items of first, second and third dimensions (Lying, Rolling, Sitting, Creeping and kneeling) were assessed on mat, while the fourth and fifth dimensions (Standing, Walking, Running and jumping) were assessed on floor.

The assessment of each item was conducted carefully and scored according to the scale scoring key (scale from 0-3).

\section{Scoring key of child's performance : \\ - $0=$ Does not initiate. \\ - $1=$ Initiates. \\ - 2 = Partially completes. \\ - 3 = Completes.}

All items were checked and scored before interpretation of child's performance in each dimension. Scores for each dimension are expressed as a percentage of the maximum possible score for that dimension. A total score was obtained by adding the scores [19]

\section{3- Gross motor function classification system ex- panded and revised:}

The GMFCS-ER was used to assess the child's functional abilities. The assessment procedures were conducted for each child separately in a large quiet room. Children were allowed to wear light comfortable clothes. The room was prepared with necessary tools and assistive devices which were needed to conduct the tasks.

The child was allowed to do the functional activities without any interference from researcher or caregiver.

Children were classified according to their functional abilities in to one of the five levels according to Palisano et al., 2006 [20]:
Level I : Walks without limitations.

Level II : Walks with limitations.

Level III: Walks using a hand-held mobility device.

Level IV: Self-mobility with limitations", can use motorized mobility.

Level V: Transported in a manual wheelchair.

\section{4-Manual ability classification system:}

The MACS was used to evaluate child's ability to handle objects in important daily activities, for example during play and leisure, eating and dressing. The evaluation focused on the most usual performances, rather than best abilities. Therefore, determination of the level was done by asking caregiver who knows about their children and not by conducting a specific assessment, because MACS is not a test. The parents and the child himself were asked [16]

Classifying child's manual abilities according to manual ability classification system:

Level I : Child handles objects easily and successfully.

Level II : Child handles most objects but with somewhat reduced quality and/or speed of achievement.

Level III: Child handles objects with difficulty; needs help to prepare and/or modify activities.

Level IV: Child handles a limited selection of easily managed objects in adapted situations.

Level V : Child does not handle objects and has severely limited ability to perform even simple actions.

Descriptive statistics was performed to present the measured variables. Spearman Correlation Coefficient was conducted to determine the correlation between spasticity levels and GMFCS-ER, GMFM-88 and MAC. The level of significance for all statistical tests was set at $p<0.05$. All statistical measures were performed through the statistical package for social studies (SPSS) version 19 for windows.

\section{Results}

Eleven children ( 5 girls and 6 boys) with hemiplegia ( 8 right hemiplegia, 3 left hemiplegia) were included in the study group. Their mean \pm SD age was $7.93 \pm 2.12$ years with maximum value of 12 years and minimum value of 5.1 years. 


\section{Clinical data:}

A- Descriptive statistics of spasticity grades, GMFCS-ER and MAC are presented in Table (1).

B- Descriptive statistics of GMFM- 88 are presented in Table (2).

C- The Correlation between spasticity of the lower and upper limbs and GMFCS-ER, MAC, and GMFM-88 is presented in the following table.

Table (1): Descriptive statistics for the spasticity grades, GMFCS-ER and MAC of the study group.

\begin{tabular}{lccc}
\hline & Median & $\begin{array}{c}25 \text { th } \\
\text { percentile }\end{array}$ & $\begin{array}{c}75 \text { th } \\
\text { percentile }\end{array}$ \\
\hline $\begin{array}{l}\text { Spasticity grades of } \\
\quad \text { Upper limb }\end{array}$ & 1 & 1 & 2 \\
$\begin{array}{l}\text { Spasticity grades of } \\
\text { Lower limb }\end{array}$ & 2 & 1 & 2 \\
GMFCS-ER & 1 & 1 & 3 \\
MAC of the affected side & 4 & 3 & 5 \\
MAC of the non-affected & 2 & 2 & 3 \\
side & & & \\
\hline
\end{tabular}

Table (2): Descriptive statistics for the GMFM-88 of the study group.

\begin{tabular}{llcl}
\hline GMFM-88 & X \pm SD & Maximum & Minimum \\
\hline Lying & $77 \pm 24.85$ & 98.04 & 25.49 \\
Sitting & $78.78 \pm 17.54$ & 98.33 & 43.33 \\
Crawling & $60.82 \pm 39.15$ & 97.62 & 0 \\
Standing & $57.8 \pm 38.05$ & 100 & 0 \\
Walking & $46.59 \pm 28.52$ & 91.67 & 6.94 \\
Total score & $64.2 \pm 28.22$ & 91.34 & 19.07 \\
\hline
\end{tabular}

$\mathrm{X}$ : Mean. $\quad$ SD: Standard Deviation.

Table (3): Correlation between spasticity of the lower and upper limbs and GMFCS-ER, MAC, and GMFM88 of the study group.

\begin{tabular}{|c|c|c|c|c|}
\hline & \multicolumn{2}{|c|}{$\begin{array}{l}\text { Spasticity grades } \\
\text { of the lower limb }\end{array}$} & \multicolumn{2}{|c|}{$\begin{array}{l}\text { Spasticity grades } \\
\text { of the upper limb }\end{array}$} \\
\hline & $r$-value & $p$-value & $r$-value & $p$-value \\
\hline GMFCS-ER & 0 & $1^{*}$ & 0.34 & $0.3^{*}$ \\
\hline $\begin{array}{l}\text { MAC of the affected } \\
\text { side }\end{array}$ & 0.15 & $0.64 *$ & 0.46 & $0.14 *$ \\
\hline GMFM Lying & -0.24 & $0.47 *$ & 0 & $1^{*}$ \\
\hline GMFM Sitting & -0.35 & $0.27 *$ & -0.17 & $0.59 *$ \\
\hline GMFM Crawling & -0.39 & $0.23 *$ & -0.27 & $0.42 *$ \\
\hline GMFM Standing & 0.03 & $0.93 *$ & -0.03 & $0.93^{*}$ \\
\hline GMFM Walking & 0 & $1^{*}$ & -0.12 & $0.72 *$ \\
\hline GMFM Total score & -0.17 & $0.59 *$ & -0.12 & $0.72 *$ \\
\hline
\end{tabular}

$r$-value: Spearman correlation coefficient.

$p$-value: Probability value.

$*$ : Non significant.

\section{Discussion}

We performed this study to determine if the spasticity grade is a major factor that affects gross and fine motor abilities in hemiplegic cerebral palsy children and it shows that there is no correlation between spasticity grade and motor abilities. The correlations between spasticity of the lower limb and GMFM-88 were weak negative nonsignificant correlations with lying score, moderate negative non-significant correlations with sitting, moderate negative non-significant correlations with crawling, weak positive non-significant correlations with standing and weak negative nonsignificant with total score. There was no correlation between spasticity of the lower limb and walking score.

The correlations between spasticity of the upper limb and GMFCS-ER were moderate positive nonsignificant correlations.

The correlations between spasticity of the upper limb and MAC were moderate positive non-significant correlations with the affected side. The correlations between spasticity of the upper limb and GMFM-88 were weak negative non-significant correlations with sitting score, crawling, standing, walking and with total score. There was no correlation between spasticity of the upper limb and lying score.

Therefore in the group of children with spastic hemiplegia included in this study, the data gathered indicates that there is a statistically non-significant correlation between spasticity grade and gross and fine motor abilities accordingly we accept our hypothesis. Our results disagree with Gorter [21] who stated that there is a statistically significant relationship between spasticity at the age 18 months and gross motor development over one year. Gorter performed his study on 17 cerebral palsy children who had initial spasticity. His study included spastic diplegic, hemiplegic and dyskinetic cerebral palsy children and the assessments was performed by a team of investigators with different backgrounds and levels of experience, which may result in a higher variance in measurements. In our study, we mainly focused on hemiplegic cerebral palsy children as unilateral spastic cerebral palsy (USCP) represents one of the most common subtypes of cp $[\mathbf{2 2 , 2 3 ]}$ and various motor impairments may be observed, depending on the timing, extent, and location of the lesions and the subsequent reorganization of the cortical pathways [24]. Also, the assessment was performed by only single physiotherapist which considered as points of strength in 
our study. The limitation of this study is the small sample size (eleven children) and we recommend repeating it on a larger sample size.

\section{Conclusion:}

In conclusion, the findings of this study indicate that spasticity is not correlated with the gross and fine motor functions in children with hemiplegic cerebral palsy.

\section{References}

1- PAPADELIS C., BUTLER E., RUBENSTEIN M., et al.: Reorganization of the somatosensory cortex in hemiplegic cerebral palsy associated with impaired sensory tracts.NeuroImage: Clinical. Elsevier, 17 (April 2017), pp., 198-212. 2018.

2- BEAMAN J., KALISPERIS R. and MILLER-SKOMORUCHA K.: The infant and child with cerebral palsy. In: Tecklin J., ed. Pediatric physical therapy 5 ed. Sydney: Lippincott Williams \& Wilkins, 187-246. 2015.

3- VERSCHUREN O., KETELAAR M., GORTER J.W., et al.: Exercise training program in children and adolescents with cerebral palsy: A randomized controlled trial. Arch Pediatr Adolesc Med., 161: 1075-1081. [Medline] [CrossRef], 2007.

4- WANG X. and WANG Y.: Gait analysis of children with spastic hemiplegic cerebral palsy. Neural Regen Res., 7 (20): 1578-1584. 2012.

5- FIGUEIREDO P., SILVA P., AVELAR S., et al.: Assessment of gait in toddlers with normal motor development and in hemiplegic children with mild motor impairment: a validity study. Braz. J. Phys. Ther., 17 (4): 359-366. 2013.

6- MOON H.: The effects of task-oriented training on hand dexterity and strength in children with spastic hemiplegic cerebral palsy: A preliminary study. Journal of physical therapy science, 29 (10): pp. 1800-1802. 2017.

7- THIBAUT A., CHATELLE C., ZIEGLER E., et al.: Spasticity after stroke: Physiology, assessment and treatment. Brain Injury, 27 (10): pp. 1093-1105 .2013.

8- MORRELL S., J.M. PEARSON, and D.D. SAUSER: Progressive bone and joint abnormalities of the spine and lower extremities in cerebral palsy. Radiographics, 22 (2): pp. 257-268. 2002.

9- HAUGH A., A. PANDYAN, and G. JOHNSON: A systematic review of the Tardieu Scale for the measurement of spasticity. Disability and Rehabilitation, 28 (15): pp. 899-907, 2006.

10- NUMANOG LU A., and M.K. GÜNEL.: Intraobserver reliability of modified Ashworth scale and modified Tardieu scale in the assessment of spasticity in children with cerebral palsy. Acta Orthopaedica et Traumatologica Turcica, 46.3: pp. 196-200, 2011.
11- BJORNSON K., BELZA B., KARTIN D., et al.: Ambulatory physical activityperformance in youth with cerebral palsy and youth who are developing typically. Phys. Ther., 87: 248-257, 2007.

12- PALISANO R., CAMERON D., ROSENBAUM P., et al.: Stability of theGross Motor Function Classification System. Developmental Medicine \& Child Neurology, 48 : 424-428, 2006.

13- RUSSEL D.J., ROSENBAUM PL., AVERY LM., et al.: Gross Moto Function Measure (GMFM 88 \& GMFM 66). User's manual clinics in developmental medicine, n.159. London: Mac. Keith. Press, 2002.

14- LUNDKVIST J., JARNLO G., GUMMESSON C., et al.: Longitudinal construct validity of the GMFM-88 total score and goal total score and the GMFM-66 score in a 5-year follow-up study. Phys. Ther., 89: 342-350, 2009.

15-ALHUSAINI A., DEAN C., CROSBIE J., et al.: Evaluation of spasticity in children with cerebral palsy using Ashworth and Tardieu scales compared with laboratory measures. J. Child. Neurol., 25: 1242-1247, 2010.

16- ELIASSON A., KRUMLINDE-SUNDHOLM L., RÖSBLAD B., et al.: The Manual Ability Classification System (MACS) for children with cerebral palsy: Scale development and evidence of validity and reliability. Dev. Med. Child. Neurol., 48 (7): 549-554, 2006.

17- GRACIES M.: Pathophysiology of spastic paresis II: emergence of muscle over activity. Muscle Nerve, 31: $552-71,2005$

18- WARD B.: Spasticity treatment with botulinum toxins. J. Neural. Transm., 115: 607-16, 2008.

19- PARK E., and KIM W.: Relationship between the Gross Motor Function Classification System and Functional Outcomes in Children with Cerebral Palsy. Indian Journal of Science and Technology, 8 (18), 2015.

20- PALISANO R., ROSENBAUM P., BARTLETT D., et al.: Content validity of the expanded and revised Gross Motor Function Classification System. Dev. Med. Child. Neurol., 50: 744-50, 2008.

21- GORTER W.: The relationship between spasticity in young children (18 months of age) with cerebral palsy and their gross motor function development, BMC Musculoskeletal Disorders, 10 (1): pp. 1-9. 2009.

22-SHEVELL M.I., DAGENAIS L. and HALL N.: REPACQ CONSORTIUM*. The relationship of cerebral palsy subtype and functional motor impairment: a populationbased study. Dev. Med. Child .Neurol., 51: 872-877, 2009.

23- STANLEY F., BLAIR E. and ALBERMAN E.: Cerebral Palsies: Epidemiology and Causal Pathways (Clinics in Developmental Medicine No. 151.) London, England: McKeith Press, 2000.

24- GORDON AM, BLEYENHEUFT Y. and STEENBERGEN B.: Pathophysiology of impaired hand function in children with unilateral cerebral palsy. Dev. Med. Child. Neurol., 55 (Suppl 4): 32-37, 2013. 


\section{العلاقة بين تشنج العضلات والقدرات الحركية لدى الأطفال المصابين بالشلل النصفى والت الحريل}

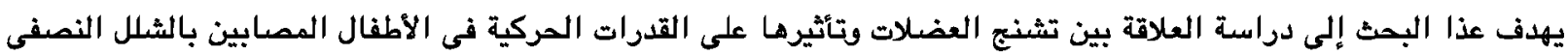

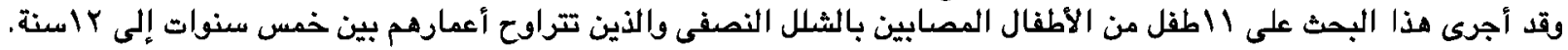
تم تجميع الأطفال من العيادات الخارجية بكلية العلاج الطبيعى جامعة القاهرة ومستشفى أبو الريش ومعهد شلل الأطفال وتقييم

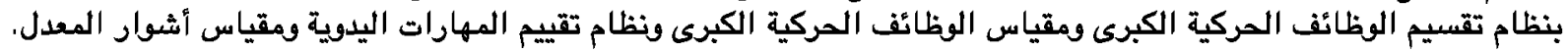
أثثبت التحليل الأحصائى عدم وجود علاقة بين تثنج العضلات والقدرات الصركية لدى هؤلاء الأطفال. 